\title{
OPEN Suitability of environmental indices in assessment of soil remediation with conventional and next generation washing agents
}

\author{
Barbara K. Klik ${ }^{\bowtie}$, Zygmunt M. Gusiatin \& Dorota Kulikowska
}

Remediation of soils contaminated with metal must ensure high efficiency of metals removal, reduce bioavailability of residual metals and decrease ecological risk. Thus, for comprehensive environmental soil quality assessment, different indices must be used. In this study, suitability of 8 indices was used for soil highly contaminated with $\mathrm{Cu}\left(7874.5 \mathrm{mg} \mathrm{kg}^{-1}\right)$, moderately with $\mathrm{Pb}\left(1414.3 \mathrm{mg} \mathrm{kg}^{-1}\right)$ and low with $\mathrm{Zn}\left(566.1 \mathrm{mg} \mathrm{kg}^{-1}\right)$, washed in batch and dynamic conditions with both conventional and next-generation washing agents. The following indices were used: modified contamination factor $\left(m C_{f}\right)$, modified contamination factor degree $\left(m C_{\text {deg }}\right)$, mobility factor $(M F)$, reduced partition index $(I R)$, potential ecological risk factor $\left(E_{r, z}\right)$, modified potential ecological risk factor $\left(E_{r, m}\right)$, potential ecological risk index $\left(R I_{z}\right)$ and modified ecological risk index $\left(R I_{m}\right)$. For $\mathrm{m} C_{f_{1}} m C_{\text {deg }}$ and $I R$ own classification scale was proposed. It was proven that most useful indices for assessment of soil pollution with metals were $m C_{f}$ and $m C_{d e g}$. The $m C_{f}$ together with the $I R$ allow to simultaneous assessment of soil pollution and stability for individual metals. These indices were appropriate for soil contaminated with different concentrations of metals, washed under both hydrodynamic conditions using various washing agents and different effectiveness of metals removal. Thus, they may be considered as most useful for evaluation of remediation method, feasibility of washing agent and assessing soil quality after washing.

An important sources of anthropogenic metals emissions are mining and metallurgy, which cause a severe environmental contamination in their immediate vicinity. Among the various elements of the environment, soils are those in which the effects of metals contamination persist for the longest time and remains even after removing the pollution source. Soil contamination with metals affects individual organisms and entire ecosystems, which is why they should be removed.

Among the available methods allowing the removal of metals there are soil washing (both in batch and dynamic conditions), with water or with washing agent (WA) of a high affinity for contaminant removal. Soil washing can remove contaminants adsorbed on soil particles by reducing the strength of bonding between pollutants and soil, increasing the hydraulic conductivity of the soil and the availability of pollution ${ }^{1}$. The decrease in capillary forces that occurs during the washing increases the mobility of the pollutants and the rate of their movement ${ }^{2}$.

Soil washing is well-established technology in many countries to remove permanently a variety of pollutants from highly contaminated soils ${ }^{3}$. The broad application of soil washing results from the possibility of using different washing agents dedicated to removal a specific pollutant and the ease in controlling the operational conditions. During soil washing, the contaminated soil is vigorously mixed with washing solution, which in turn reduces the remediation time and provides high pollutant removal. Another advantage of soil washing includes reducing the volume of soil to be treated by concentrating pollutants into fine particles, which reduces the remediation cost. Among different remediation methods, soil washing characterizes with a high public acceptance ${ }^{4}$.

This method requires soil excavation and soil transportation to a place of disposal. In practice, in situ methods, i.e. carried out directly in contaminated sites are also preferred ${ }^{5}$. For effective washing technology it is 
recommended to determine firstly the optimal parameters in the laboratory studies. This approach reduces the risk of failure and gives the opportunity to view and to resolve potential difficulties that may appear in the fullscale operation ${ }^{6}$. Such tests are conducted under batch and/or dynamic conditions (column leaching mode). In these methods, however, different mechanisms of metals transport occur ${ }^{7}$. In batch experiments, sorption/ desorption of metals is determined under equilibrium conditions, whereas in column washing under nonequilibrium conditions, which run slower than under batch washing ${ }^{8}$. The efficiency of metals removal via soil washing in batch and dynamic conditions can vary widely. The efficiency of washing at the level of $70-80 \%$ is considered to be substantial. However, the efficiency above $50 \%$, is still considered as cost-effective, and possible to use on a pilot and technical scale ${ }^{6}$.

During the past decades, studies have evaluated the effectiveness of removal of metals from the soil with various WAs, such as acids, salts and chelating agents ${ }^{9-13}$. Natural and environmentally friendly WAs, such as dissolved organic matter or soluble humic substances, can be also used to remove metals from contaminated soils with high efficiency ${ }^{14-18}$. Despite the process efficiency, some metals still remain in soil after treatment. Therefore, the quality of treated soil must consider several aspects, i.e. pollution level, metal stability and environmental risk. The key to assess soil contamination with residual metals can be using soil pollution indices. They are regarded as a tool and guide for an extensive evaluation of the state of the soil environment ${ }^{19}$. The indices are widely used and can be developed on different criteria, e.g. individual metals contamination (e.g. enrichment factor, EF; geoaccumulation index, $\mathrm{I}_{\text {geo }}$; contamination factor, $\left.C_{\mathrm{f}}\right)^{19-22}$ and multi-metals contamination (e.g. contamination degree, $\left.C_{d e g}\right)^{21,23}$. Other indices are based on the concentration of metals in their individual chemical forms, along with having great importance in determining the mobility of metals (as mobility factor, $M F$ ) and strength of metal binding with mineral-organic soil components (e.g. reduced partition index, $I R)^{24,25}$.

Historically, most of these indices were used mainly for assessment of pollution level in sediments, then were adopted to soils contaminated with different metals and of different level of contamination ${ }^{19,20,26}$. There are some attempts to use them for assessment soil quality after remediation, but only with the use of selected, single indices, mainly concerning environmental risk $^{27,28}$. However, as these indices were originally used for sediments, they are based on comparison between current metal concentrations with their geochemical background levels. Although, some of these indices can be used for urban and agricultural soils with elevated metal concentrations ${ }^{19}$, their using for highly contaminated soils can be inconclusive. For industrial objects connected with metal smelting, however, estimation of soil quality based on pollution indices is missing ${ }^{26}$.

In highly contaminated soils, despite a considerable decreasing of metal concentration after soil washing, the difference between residual metal concentrations in soil and geochemical background levels can still be high, indicating high pollution level, the same as for soil before remediation. However, taking into account that the purpose of remediation is decrease metal concentration to legislative level, regarding the current and, if possible, planned use of the land, more reliable for soil pollution assessment after remediation can be using the indices, at which current metal concentration will be referred to permissible levels in remediated soil instead of geochemical background. This was done in this study: modification of existing indices, based on soil pollution with single- and multi-metals, as well as own classification of the indices was proposed. Moreover, suitability of these modified indices, as well as indices based on strength of metal binding in soil and on ecological risk of metals, were assessed for soil after remediation. In order to check the indices at various levels of metal contamination and different remediation efficiency, all indices were calculated for: (1) soil of different degree of contamination by various metals (heavily polluted with $\mathrm{Cu}$, moderately with $\mathrm{Pb}$ and weakly with $\mathrm{Zn}$ ), (2) washed in batch and dynamic conditions, and (3) using both conventional ( $\mathrm{Na}_{2} \mathrm{EDTA}$ ) and next-generation WAs (dissolved organic matter, DOM; soluble humic-like substances, HLS and soluble humic substances, SHS).

\section{Materials and methods}

Soil. Soil taken from the top layer of agriculture area was used for the study. After air drying, the samples were ground and sieved through a $2 \mathrm{~mm}$ sieve. To obtain metals contamination similar to soils from the metallurgical area, the soil was spiked with a mixture of $\mathrm{Cu}\left(\mathrm{NO}_{3}\right)_{2}, \mathrm{~Pb}\left(\mathrm{NO}_{3}\right)_{2}$ and $\mathrm{Zn}\left(\mathrm{NO}_{3}\right)_{2}$, according to the procedure of Chaiyaraksa and Sriwiriyanuphap ${ }^{29}$ and incubated for three months at room temperature. Metals values were assumed according to concentrations in soils around the Legnica smelter in Poland ${ }^{18}$. Because the aim of this study was to check the suitability of different indices to assess degree of soil contamination (and subsequently soil remediation), it was assumed that soil must be contaminated with metals of different concentration: from very high (several times above permissible concentration) to low (below permissible concentration). Such concentration range is necessary to select universal indices and to propose own classification scale for these indices. $\mathrm{So}$, in this study soil was very highly contaminated with $\mathrm{Cu}$, moderately with $\mathrm{Pb}$ and weakly with $\mathrm{Zn}$.

Before soil treatment, soil properties were determined (Table 1). Based on the granulometric composition, soil was characterized as sandy loam with a low content of organic matter (3.4\%) and slightly acidic pH (6.4). Total concentration of metals and their distribution were also shown in Table 1.

Washing agents (WAs). Two groups of WAs were used in this study: (1) waste-derived in form of soluble organics from municipal sewage sludge (SS_WAs) and (2) commercially available $\mathrm{Na}_{2}$ EDTA.

As SS_WAs, three different washing solutions were used: DOM, HLS and SHS. The previous study presented a detailed extraction procedure and characteristics of the used washing solutions ${ }^{18,30}$. Briefly, WAs were extracted $(1: 10$ ratio $(\mathrm{w} / \mathrm{v}))$ with water (DOM) and $0.1 \mathrm{M} \mathrm{NaOH}\left(\mathrm{HLS}\right.$ and SHS) from the dried sewage sludge $\left(105^{\circ} \mathrm{C}\right)$. In addition, before the extraction of SHS, dissolved substances (i.e. sugars and proteins), waxes, and bitumen were removed from the sludge, as described in paper by Klik et al. ${ }^{30}$.

The methods of soil remediation and WAs were selected in such way to indicate various efficiency of metals removal from soil, e.g. $\mathrm{Na}_{2}$ EDTA and HLS was extremely effective in removal of all metals, DOM was extremely 


\begin{tabular}{|c|c|c|c|}
\hline Soil properties & \multicolumn{3}{|l|}{ Value } \\
\hline Bulk density $\left(\mathrm{g} \mathrm{ml}^{-1}\right)$ & \multicolumn{3}{|c|}{$1.23( \pm 0.08)$} \\
\hline Porosity $(\%)$ & \multicolumn{3}{|c|}{$54( \pm 2.3)$} \\
\hline Sand $(\%)$ & \multicolumn{3}{|c|}{$56( \pm 1.6)$} \\
\hline Silt (\%) & \multicolumn{3}{|c|}{$39( \pm 0.16)$} \\
\hline Clay $(\%)$ & \multicolumn{3}{|c|}{$5( \pm 0.21)$} \\
\hline Texture & \multicolumn{3}{|c|}{ Sandy loam } \\
\hline $\mathrm{pH}$ & \multicolumn{3}{|c|}{$6.4( \pm 0.1)$} \\
\hline Organic matter (\%) & \multicolumn{3}{|c|}{$3.4( \pm 0.08)$} \\
\hline Cation exchange capacity $\mathrm{cmol}(+) \mathrm{kg}^{-1}$ & \multicolumn{3}{|c|}{$17.2( \pm 0.7)$} \\
\hline Total $\mathrm{Cu}\left(\mathrm{mg} \mathrm{kg}^{-1}\right)$ & \multicolumn{3}{|c|}{$7874.5( \pm 23.06)$} \\
\hline Total Pb (mg kg-1) & \multicolumn{3}{|c|}{$1414.3( \pm 11.6)$} \\
\hline Total Zn $\left(\mathrm{mg} \mathrm{kg}^{-1}\right)$ & \multicolumn{3}{|c|}{$566.1( \pm 4.2)$} \\
\hline Heavy metals distribution & $\mathrm{Cu}(\%)$ & $\mathrm{Pb}(\%)$ & $\mathrm{Zn}(\%)$ \\
\hline Exchangeable and acid-soluble fraction (F1) & 86 & 74 & 76 \\
\hline Reducible fraction (F2) & 9 & 15 & 7 \\
\hline Oxidizable fraction (F3) & 1 & 6 & 3 \\
\hline Residual fraction (F4) & 4 & 5 & 14 \\
\hline
\end{tabular}

Table 1. Selected physicochemical soil properties (mean value \pm standard deviation, $n=3$ ).

a)

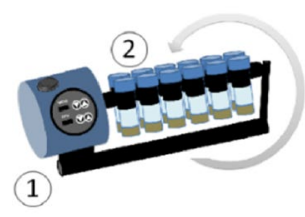

b)

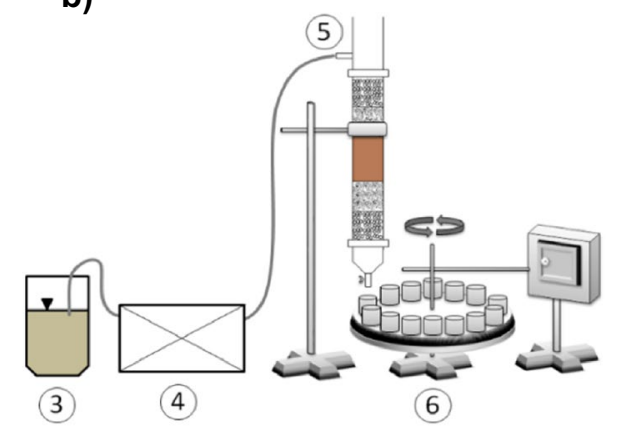

(1) Intelli shaker

(2) set of samples

(3) container with washing agent

(4) peristaltic pump

(5) column reactor

(6) automatic sampling device

Figure 1. Set-up for metals removal from soil under (a) batch and (b) dynamic conditions.

effective in $\mathrm{Cu}$ removal and with low efficiency in $\mathrm{Pb}$ removal, $\mathrm{SHS}$ was effective in $\mathrm{Pb}$ removal etc.). Such scope of experiments allows to select the most universal indices of environmental quality of soil and to propose own scale for classification of these indices.

Batch washing experiments. The washing experiments under batch conditions were conducted in polyethylene tubes $(50 \mathrm{~mL})$ with soil to solution ratio of $1 / 40(\mathrm{w} / \mathrm{v})$. The samples were shaken in a mechanical shaker at $150 \mathrm{rpm}$ at room temperature (Fig. 1a). The concentration of SS_WAs was $5 \mathrm{~g} \mathrm{C} \mathrm{L}^{-1}$. The concentration of $\mathrm{Na}_{2}$ EDTA was typical used for soil treatment with the chelator $\left(0.005 \mathrm{~N} ; 0.64 \mathrm{~g} \mathrm{C} \mathrm{L}^{-1}\right)^{31}$. In all WAs, the $\mathrm{pH}$ was adjusted to 4 and the contact time was $2 \mathrm{~h}$ (established in the previous study based on preliminary tests). After washing, samples were collected, centrifuged, and filtered through Whatman filter papers 42 . The supernatants were acidified with $\mathrm{HNO}_{3}$ and kept at $4{ }^{\circ} \mathrm{C}$ before $\mathrm{Cu}, \mathrm{Pb}$, and $\mathrm{Zn}$ analysis.

Dynamic washing experiments. The experiments were carried out in a column reactor equipped with a set of two sieves (supporting and closing) and two layers of rinsed gravel (2-4 mm and 1-2 mm) (Fig. 1b). The column reactor with length of $30 \mathrm{~cm}$ and radius of $1.5 \mathrm{~cm}$ was packed with $200 \mathrm{~g}$ gravel and $50 \mathrm{~g}$ of contaminated soil.

The tests were carried out at concentration and $\mathrm{pH}$ of WAs the same as in batch washing. Washings solutions were added to the reactor from the top and the eluate was collected from the bottom of the reactor by the automatic sampling device over time. Samples were taken every hour. Before proper soil washing procedure, distilled water was applied for $1 \mathrm{~h}$ to saturate the soil. Pore volume for the column reactor was $56.8 \mathrm{ml}$. The research was conducted at 2 different flow rates $\left(0.5 \mathrm{ml} \mathrm{min}^{-1}\right.$ and $\left.1 \mathrm{ml} \mathrm{min}^{-1}\right)$, for each washing solution for $24 \mathrm{~h}$. All column experiments were conducted at room temperature, under laboratory conditions. 
The environmental indices for soil remediation assessment. In the present study, different environmental indices were used to assess the efficiency of batch and dynamic soil washing with SS_WAs agents and $\mathrm{Na}_{2} \mathrm{EDTA}$. These indices, including total metals concentrations in soil and metals distribution in chemical fractions, were divided into three groups:

Indices based on soil pollution with metals.

(a) single-metal soil pollution.

Modified contamination factor $\left(\mathrm{m} C_{f}\right)$. The contamination factor $\left(C_{f}\right)$, originally proposed by Hakanson ${ }^{21}$ for sediments, now is commonly used to assess soil contamination with metals ${ }^{23,32-35}$. For $C_{f}$ calculation, mostly preindustrial or geochemical background concentrations of metals are used. The use of such reference values can be not reliable for assessment of metal pollution in highly contaminated before and after remediation. This is because in remediated soil achieving metal concentration on the level of geochemical background is impossible and it is not legally required. According to Polish Environmental Protection Law ${ }^{36}$, remediation is based on the removal or reduction the amount of substances causing the risk from soil and groundwater to the level of limit values, their control and limitation of migration, so that the contaminated area ceases to pose a threat to human health or the state of the environment, taking into account the current and the planned land use. Therefore, in this study for the assessment of metal pollution in contaminated and post-remediated soil, original $C_{f}$ factor was modified to $\mathrm{m}_{f}$ taking as reference of metal concentration, not preindustrial/geochemical background, but the limit values for metals in industrial soil given in a national regulation (here the Ordinance of the Minister of Environment ${ }^{37}$ ). The $\mathrm{mC}_{f}$ was calculated according to the following formula:

$$
m C_{f}^{i}=\frac{C_{s}^{i}}{C_{r}^{i}}
$$

where: $C_{s}$ is the concentration of metals in soil sample, $C_{r}$ is the limit value for a given metal in soil according to $\mathrm{OME}^{37}: 600 \mathrm{mg} \mathrm{kg}^{-1}$ for $\mathrm{Cu}$ and $\mathrm{Pb}$ and $2000 \mathrm{mg} \mathrm{kg}^{-1}$ for $\mathrm{Zn}$. The $\mathrm{mC}_{f}$ was categorized into five levels: $\mathrm{mC}_{f} \leq 1$ means that soil meets the national quality standard for industrial sites, $1<\mathrm{m} C_{f} \leq 2$ means weakly to moderately contaminated soil, $2 \mathrm{~m}<C_{f} \leq 3$ means moderately to strongly contaminated soil, $3<\mathrm{mC}_{f} \leq 4$ means strongly to extremely contaminated soil and $\mathrm{mC}_{f}>4$ means extremely contaminated soil.

(b) multi-metal soil pollution.

Modified contamination degree $\left(\mathrm{mC}_{\text {deg }}\right)$. The overall assessment of sediment contamination with metals was introduced by Hakanson ${ }^{21}$ as a contamination degree $\left(C_{d e g}\right)$. The $C_{d e g}$ is a sum of the $C_{f}$ for individual metals. Like the $C_{f}$, the $C_{\operatorname{deg}}$ was also used to assess soil contamination with metals $s^{23,32-35}$. Because in the present study, the $C_{f}$ was changed for $\mathrm{m} C_{f}$, consequently the $C_{\text {deg }}$ was changed for $\mathrm{m} C_{\text {deg }}$ and the $\mathrm{mC}_{\text {deg }}$ equation was modified as follows:

$$
m C_{\text {deg }}=\sum_{i=l}^{n} m C_{f}^{i} \times w
$$

where: $\mathrm{mC}_{f}$ is the modified contamination factor calculated in Eq. (1), $n$ is the number of metals in soil, $w$ is factor weight resulting from the value of $m C_{f}$, i.e. when $m C_{f} \leq 1$ then $w=1$ or when $m C_{f}>1$ then $w=n$. The classification of $m C_{d e g}$ was simplified and two categories of soil quality were proposed: $\mathrm{mC}_{\operatorname{deg}} \leq n$ means that soil meets the national quality standards for industrial sites and $\mathrm{mC}_{\operatorname{deg}}>n$ means that soil does not meet the national quality standards.

Indices based on the strength of metal binding in soil. Mobility factor $(M F)$. The $M F$ is used to assess changes in metal mobility, and is defined as the ratio of metal concentration in the mobile fraction to the sum of metal concentrations in all analyzed fractions ${ }^{25}$. The $M F$ (based on the BCR fractionation procedure) is expressed by the following equation:

$$
M F=\frac{C_{F 1}}{C_{F 1}+C_{F 2}+C_{F 3}+C_{F 4}} \times 100 \%
$$

where: $\mathrm{C}_{F 1}, \mathrm{C}_{F 2}, \mathrm{C}_{F 3}$, and $\mathrm{C}_{F 4}$ are the concentrations of metal in exchangeable/acid soluble, reducible, oxidizable and residual fractions, respectively. With the $M F$, metal can be immobile $(<1 \%)$, weakly mobile $(1-10 \%)$, moderately mobile (11-30\%), highly mobile (31-50\%) and very highly mobile ( $>50 \%)$.

Reduced partition index $(I R)$. The $I R$ informs about the strength of metals binding with mineral-organic soil components. When $I R$ is close to 0 , metal occurs in an easily soluble and exchangeable form, while $I R$ close to 1 means that a given metal dominates in stable forms, mainly in the residual form ${ }^{24,25}$.

$$
I R=\frac{\sum_{i=1}^{k} i^{2} F_{i}}{k^{2}}
$$


where: $i$ is the index number of the sequential extraction step, for the weakest to the strongest $(k)$ (in the BCR procedure, $k=4)$, and $F_{\mathrm{i}}$ is the percentage content of the considered metal in a i-fraction. Because the $I R$ corresponds with the $M F$, the following classification was proposed: lack of stability $(I R \leq 0.1)$, low stability $(0.1<I R \leq 0.3)$, medium stability $(0.3<I R \leq 0.5)$, elevated stability $(0.5<I R \leq 0.7)$, high stability $(0.7<I R \leq 0.9)$ and very high stability $(I R>0.9)$.

Indices based on ecological risk from metals. Potential ecological risk factor $\left(E_{r}\right)$. The $E_{r}$ assesses the impact of individual metal including their various toxicological effects ${ }^{21}$. The $E_{r}$ is also used to evaluate the ecological risk for sediments and soils ${ }^{38,39}$. In the present study, the $E_{r}$ was calculated and compared according to the formula given by Hakanson ${ }^{21}$ and used in the study by Zhu et al. ${ }^{40}$ (in this study noted as $E_{r, \mathrm{Z}}^{i}$ ) and according to our modification (in this study noted as $E_{r, \mathrm{~m}}^{i}$ ) using $\mathrm{m} C_{f}$ instead of $C_{f}$ :

$$
\begin{gathered}
E_{r, Z}^{i}=T_{r}^{i} \times C_{f}^{i} \\
E_{r, m}^{i}=T_{r}^{i} \times m C_{f}^{i}
\end{gathered}
$$

where: $T_{r}$ is the toxic-response factor for a given metal ( 5 for $\mathrm{Cu}$ and $\mathrm{Pb}, 1$ for $\mathrm{Zn}$, Hakanson ${ }^{21}$ ), $\mathrm{mC}_{f}^{i}$ is the modified contamination factor.

Because in this study, similarly as in study by Zhu et al. ${ }^{40}$, the metals with the highest $T_{\mathrm{r}}(\mathrm{Hg}, \mathrm{Cd}, \mathrm{As})$ were not analyzed, we assumed the same classification of soil ecological risk as Zhu et al..$^{40}$ : low risk $\left(E_{r} \leq 15\right)$, moderate risk $\left(15<E_{r} \leq 30\right)$, considerable risk $\left(30<E_{r} \leq 60\right)$, high risk $\left(60<E_{r} \leq 120\right)$, and very high risk $\left(E_{r}>120\right)$.

Potential ecological risk index $(R I)$. The $R I$ is defined as the sum of $E_{r}$ (Hakanson $\left.{ }^{21}\right)$. Because in the present study $E_{r, \mathrm{Z}}^{\mathrm{i}}$ and $E_{r, \mathrm{~m}}^{\mathrm{i}}$ were established, therefore two $R I$ were also calculated according to the Eqs. $(7,8)$ :

$$
\begin{aligned}
& R I_{Z}=\sum_{i=l}^{n} E_{r, Z}^{i} \\
& R I_{m}=\sum_{i=l}^{n} E_{r, m}^{i}
\end{aligned}
$$

According to the classification of the $E_{r}$ the classification of $R I$ was different than that originally given by Hakanson $^{21}$ : low risk $(R I \leq 50)$, moderate risk $(50<R I \leq 100)$, considerable risk $(100<R I \leq 200)$, and very high risk $(R I>200)^{41}$.

Analytical methods. The equilibrium $\mathrm{pH}$ of soil was measured with a pH meter (Hanna Instruments) in distilled water (1:2.5 ratio, $\mathrm{m} / \mathrm{V})$. The soil texture was determined using a Mastersizer 2000 particle size analyzer. The content of organic matter was determined by the Tiurin method and CEC was measured according to the Kappen's method ${ }^{42}$. The concentration of metals in soil was determined with Flame Atomic Absorption Spectrometry (FAAS) using a spectrometer equipped with an automatic sample introduction and dilution system (SIPS). The samples were mineralized in a mixture of concentrated $\mathrm{HCl}$ and $\mathrm{HNO}_{3}$ before determination of total metals content. Mineralization was carried out in a microwave oven (MarsXpress, CEM). Metals distribution was determined according to a modified BCR procedure given by Pueyo et al. ${ }^{43}$, the following fractions were determined: exchangeable and acid-soluble fraction (F1); reducible fraction (F2); oxidizable fraction (F3); and a residual fraction $(\mathrm{F} 4)$.

The obtained results are averages of three replicate measurements. The statistical analyses were performed with Statistica 13.1 (StatSoft, Inc.). One-way analysis of variance (ANOVA), followed by Tukey's HSD test was employed to indicate significant differences between means for metal removal efficiencies and environmental indices in soil treated with different WAs under batch and dynamic soil washing. Validation of the data was carried out through comparing total metal content obtained by total digestion with sequential extraction of metals. The metal recovery ratio $(\mathrm{R})$ was calculated as follows:

$$
\mathrm{R}=\frac{C_{F 1}+C_{F 2}+C_{F 3}+C_{F 4}}{C_{\text {total }}} \times 100
$$

where: $C_{F 1}, C_{F 2}, C_{F 3}$, and $C_{F 4}$ is the concentration of metal in a given fraction, $C_{\text {total }}$ is the total metal concentration.

\section{Results and discussion}

The removal efficiency of metals. Comparing the metals removal under different soil washing conditions, the batch washing was more efficient compared to dynamic washing. This may be due to the way of contact between the soil and WAs, which is more vigorous under batch conditions and a higher ratio of soil weight to volume of washing solution in comparison to dynamic washing. Although higher metal removal under batch than dynamic soil washing is typical phenomenon ${ }^{4-46}$, our intention was to show the different efficiency of metals removal and their different fractional distribution in batch- and dynamic-washed soil in terms of the possibility of assessing the usefulness of modified environmental indices for soils with different remediation efficiency. 

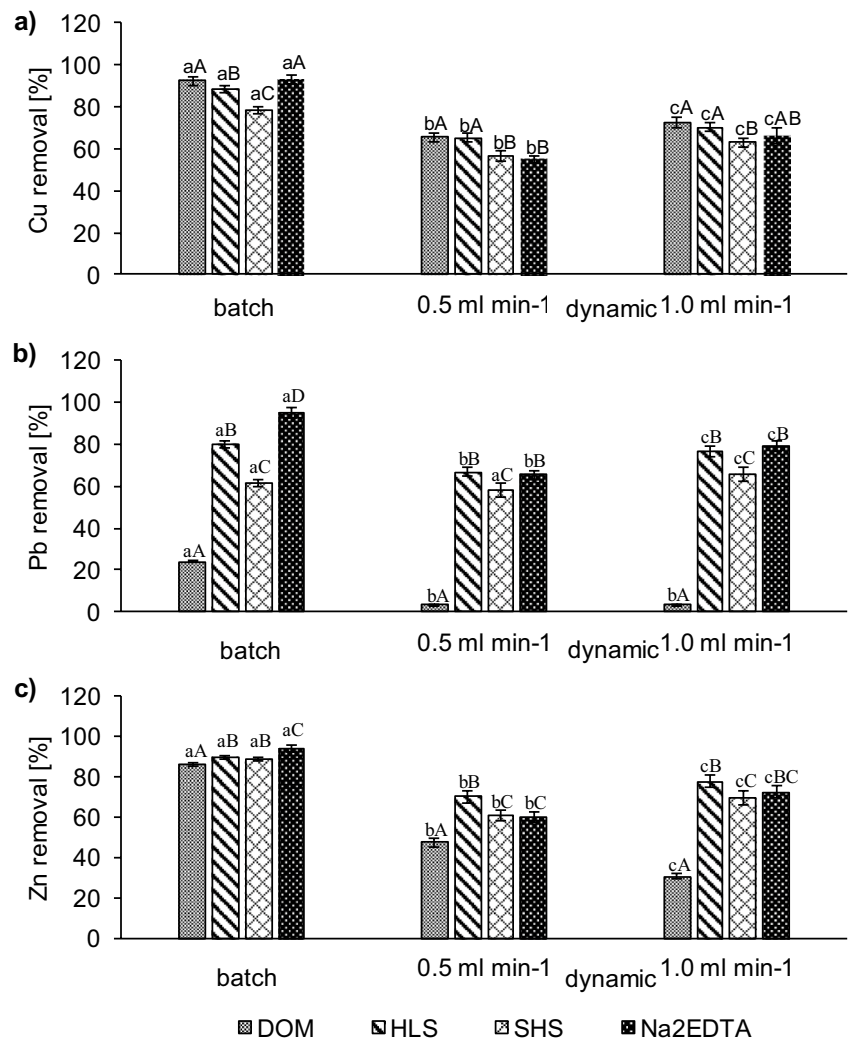

Figure 2. Comparison of the efficiency of metal removal from soil under batch and dynamic washing with DOM, HLS, SHS and $\mathrm{Na}_{2}$ EDTA: (a) $\mathrm{Cu},(\mathbf{b}) \mathrm{Pb}$, and (c) $\mathrm{Zn}$. Different letters indicate statistical differences at $p<0.05$ (Statistica 13.1) between the efficiency of metal removal for different washing conditions (abc) and between the efficiency of metal removal with washing agents for a given washing condition (ABC).

In the present study, the soil was contaminated to the largest extent with $\mathrm{Cu}$, which exceeded over 13 times permissible limit for industrial soils according to Polish legislative ${ }^{37}$. Therefore, $\mathrm{Cu}$ removal mostly affected the overall efficiency of soil remediation.

Under batch conditions with all tested WAs, the average efficiency of $\mathrm{Cu}$ removal was $88 \%$ (ranging from $79 \%$ for SHS to $93 \%$ for $\mathrm{Na}_{2} \mathrm{EDTA}$ ). Under dynamic conditions, the higher efficiency of $\mathrm{Cu}$ removal, and consequently lower residual $\mathrm{Cu}$ concentration in soil, was at $1 \mathrm{ml} \mathrm{min}^{-1}$ than at $0.5 \mathrm{ml} \mathrm{min}^{-1}$ flow rate (Fig. 2). DOM and $\mathrm{Na}_{2}$ EDTA removed the highest amount of $\mathrm{Cu}$ from soil under batch conditions $(>92 \%)$, while under dynamic conditions, DOM and HLS were the most effective for $\mathrm{Cu}$ removal (the efficiency $>70 \%$ ). Similarly, higher $\mathrm{Pb}$ removal was obtained in batch than dynamic conditions. However, in both hydrodynamic conditions, most effective in $\mathrm{Pb}$ removal were $\mathrm{HLS}$ and $\mathrm{Na}_{2}$ EDTA. In contrast to $\mathrm{Cu}, \mathrm{DOM}$ was able to remove only $24 \%$ of $\mathrm{Pb}$ under batch washing and only $3 \%$ (on average) under dynamic conditions. As in contaminated soil, Zn concentration was the lowest, compared to $\mathrm{Cu}$ and $\mathrm{Pb}$, and its removal efficiency with DOM, HLS, SHS and $\mathrm{Na}_{2} \mathrm{EDTA}$ were high in both washing conditions. However, batch conditions were also more favourable than dynamic conditions. For example, the efficiency of $\mathrm{Zn}$ removal with HLS was $90 \%$ under batch conditions (in washed soil $\mathrm{Zn}$ remained mainly in F4 fraction) and 70-78\% under dynamic condition at both flow rates.

The difference in metal removal with tested washing agents was related to their characteristics and affinity to individual metals. The washing agents extracted from sewage are composed of multiple organic compounds and functional groups. DOM contains mainly low-molecular-weight organics and fulvic acids. HLS contains both low-molecular-weight organics and macromolecular compounds (fulvic and humic acids), whereas SHS are mainly consist of fulvic and humic acids ${ }^{3}$ Among different organic functional groups, carboxyl (carboxyl-C) and amino ( $N$-alkyl-C) groups readily interact with metals ${ }^{47}$. In all washing agents derived from sewage sludge, carboxyl (dissociated and undissociated) and unprotonated amino groups were the most abundant and the intensities in the infrared spectra for these groups decreased in the order DOM $>$ HLS $>\mathrm{SHS}^{30}$. This can explain higher DOM efficiency in metal removal, especially $\mathrm{Cu}$ and $\mathrm{Zn}$. In contrast, higher $\mathrm{Pb}$ removal with HLS and SHS than DOM suggests that its removal depends more on the presence of functional groups in macromolecular organic compounds in washing agents, especially humic acids than on functional groups in low-molecularweight organics.

Because better removal of $\mathrm{Cu}, \mathrm{Pb}$ and $\mathrm{Zn}$ under dynamic conditions was at higher flow rate, to compare the suitability of the many commonly used indices for assessment remediation efficiency and soil quality, the results from batch and dynamic washing at flow rate of $1.0 \mathrm{ml} \mathrm{min} \mathrm{m}^{-1}$ were selected. 


\begin{tabular}{|c|c|c|c|c|c|c|c|c|}
\hline \multirow[b]{2}{*}{ Metal } & \multirow[b]{2}{*}{ Washing agent } & \multirow[b]{2}{*}{ Washing mode } & \multirow[b]{2}{*}{ Total metal concentration $\left(\mathrm{mg} \mathrm{kg}^{-1}\right)$} & \multicolumn{4}{|c|}{ Metal fraction $\left(\mathrm{mg} \mathrm{kg}^{-1}\right)$} & \multirow[b]{2}{*}{$\mathbf{R}(\%)$} \\
\hline & & & & F1 & F2 & F3 & F4 & \\
\hline \multirow{9}{*}{$\mathrm{Cu}^{*}$} & \multicolumn{2}{|l|}{ Unwashed } & 7874.5 & 6655.2 & 660.4 & 96.0 & 327.6 & 88.8 \\
\hline & \multirow{2}{*}{ DOM } & Batch & 600.5 & 134.7 & 78.2 & 52.5 & 267.9 & 94.6 \\
\hline & & Dynamic & 2153.5 & 1236.3 & 391.4 & 90.8 & 311.6 & 94.3 \\
\hline & \multirow{2}{*}{ HLS } & Batch & 906.9 & 386.3 & 94.8 & 78.2 & 298.6 & 93.6 \\
\hline & & Dynamic & 2343.5 & 1486.3 & 412.5 & 84.9 & 306.4 & 97.7 \\
\hline & \multirow{2}{*}{ SHS } & Batch & 1685.1 & 1048.0 & 148.6 & 69.1 & 311.2 & 123.4 \\
\hline & & Dynamic & 2918.0 & 1968.0 & 461.3 & 107.5 & 317.6 & 97.6 \\
\hline & \multirow{2}{*}{$\mathrm{Na}_{2}$ EDTA } & Batch & 529.1 & 108.2 & 151.2 & 85.1 & 308.5 & 98.3 \\
\hline & & Dynamic & 2659.5 & 1808.2 & 451.2 & 89.1 & 320.1 & 99.9 \\
\hline \multirow{9}{*}{$\mathrm{Pb}^{*}$} & \multicolumn{2}{|l|}{ Unwashed } & 1414.3 & 1036.6 & 207.8 & 89.0 & 67.6 & 93.5 \\
\hline & \multirow{2}{*}{ DOM } & Batch & 1076.8 & 731.1 & 138.5 & 74.9 & 62.3 & 95.7 \\
\hline & & Dynamic & 1365.3 & 991.1 & 188.5 & 82.9 & 64.6 & 97.0 \\
\hline & \multirow{2}{*}{ HLS } & Batch & 281.3 & 84.2 & 43.6 & 79.3 & 62.1 & 93.7 \\
\hline & & Dynamic & 337.3 & 134.2 & 50.3 & 89.3 & 65 & 97.6 \\
\hline & \multirow{2}{*}{ SHS } & Batch & 545.9 & 290.6 & 63.1 & 80.9 & 64.7 & 104.2 \\
\hline & & Dynamic & 481.1 & 272.6 & 61.1 & 84.1 & 67 & 102.2 \\
\hline & \multirow{2}{*}{$\mathrm{Na}_{2}$ EDTA } & Batch & 71.5 & 3.9 & 3.2 & 24.8 & 42.7 & 99.1 \\
\hline & & Dynamic & 301.3 & 163.9 & 53.2 & 28.3 & 50.6 & 98.2 \\
\hline \multirow{9}{*}{$\mathrm{Zn}^{*}$} & \multicolumn{2}{|l|}{ Unwashed } & 566.1 & 423.7 & 40.6 & 17.8 & 77.3 & 101.4 \\
\hline & \multirow{2}{*}{ DOM } & Batch & 73.8 & 5.1 & 4.1 & 11.1 & 54.0 & 93.5 \\
\hline & & Dynamic & 393.1 & 251.2 & 36.1 & 16.4 & 70.6 & 95.2 \\
\hline & \multirow{2}{*}{ HLS } & Batch & 58.4 & 2.7 & 2.1 & 7.1 & 42.8 & 92.6 \\
\hline & & Dynamic & 127.1 & 22.1 & 22.1 & 15.1 & 68.8 & 100.7 \\
\hline & \multirow{2}{*}{ SHS } & Batch & 65.0 & 2.0 & 2.1 & 8.7 & 47.5 & 96.5 \\
\hline & & Dynamic & 171.8 & 61.9 & 30.6 & 16.7 & 67.2 & 102.6 \\
\hline & \multirow{2}{*}{$\mathrm{Na}_{2}$ EDTA } & Batch & 34.0 & 2.2 & 1.8 & 6.4 & 22.4 & 98.8 \\
\hline & & Dynamic & 158.2 & 86.8 & 23.7 & 13.4 & 42.4 & 105.1 \\
\hline
\end{tabular}

Table 2. Total metal concentrations and their individual fractions in soil before and after soil washing under batch and dynamic conditions. ${ }^{*}$ Limit values for industrial soils in Poland: $\mathrm{Cu} 600 \mathrm{mg} \mathrm{kg}{ }^{-1}, \mathrm{~Pb} 600 \mathrm{mg} \mathrm{kg}^{-1}, \mathrm{Zn}$ $2000 \mathrm{mg} \mathrm{kg}^{-1}\left(\mathrm{OME}^{37}\right)$, metal fractions: $\mathrm{F} 1$ is the exchangeable and acid soluble, F2 is the reducible, F3 is the oxidizable, $\mathrm{F} 4$ is the residual, $\mathrm{R}$ is the $\mathrm{HM}$ recovery ratio.

Patterns of metal distribution in soil washed under batch and dynamic conditions. Total content of metal measured in raw or treated soils is not a direct indicator of hazardous ecological consequences. Thus, each metal in the contaminated soil and soil after batch and dynamic washings was fractionated into different chemical fractions. According to Minkina et al. ${ }^{48}$, metals distribution should be determined in soil from each remediation action. The results on the changes in metals concentrations in individual fractions are shown in Table 2. The recovery values (R) for metals fractionation were in the ranges of $88.8-123.4 \%$ for $\mathrm{Cu}$, 93.5-104.2\% for $\mathrm{Pb}$, and $92.6-105.1 \%$ for $\mathrm{Zn}$. The values are considered to be satisfactory for the quality of the results on metals fractionation ${ }^{49,50}$.

The results clearly demonstrated that the distribution patterns for individual metals depended on the soil washing conditions and the type of WA. The results have shown that the most mobile F1 fraction was considerably removed with the most of tested WAs under batch and dynamic conditions (Table 2).

The share of $\mathrm{F} 1$ fraction for $\mathrm{Cu}$ in soil washed under batch conditions was lower than under dynamic conditions, which is associated with lower process efficiency for these washing conditions ("The removal efficiency of metals" section). In batch conditions small share of $\mathrm{Cu}$ in $\mathrm{F} 1$ fraction was in soil washed with $\mathrm{Na}_{2} \mathrm{EDTA}$ (108.2 $\left.\mathrm{mg} \mathrm{kg}^{-1} ; 16.6 \%\right)$ and DOM $\left(134.7 \mathrm{mg} \mathrm{kg}^{-1} ; 25.3 \%\right)$, and the largest in soil washed with SHS $\left(1048 \mathrm{mg} \mathrm{kg}^{-1}\right.$; $66.5 \%)$. Under dynamic conditions, despite decreasing of total $\mathrm{Cu}$, its distribution in all washed soils was similar to that in unwashed soil with the same order of fractions as F1 $>$ F2 $>$ F4 $>$ F3 (Table 2). It must be emphasized that under dynamic conditions, the greatest decrease in the $\mathrm{Cu}$ concentration in the F1 fraction was recorded for DOM. It means that although in batch conditions effectiveness of DOM and $\mathrm{Na}_{2} \mathrm{EDTA}$ for $\mathrm{Cu}$ removal from F1 was similar, in dynamic conditions more favorable for $\mathrm{Cu}$ removal was DOM.

In the case of $\mathrm{Pb}$, although batch washing was more effective than dynamic washing, distribution pattern of $\mathrm{Pb}$ in washed soil in both conditions was similar. However, this phenomenon was observed only with SS_WAs. A different pattern was noted in $\mathrm{Na}_{2} \mathrm{EDTA}$-washed soil: in soil washed under batch conditions $\mathrm{F} 4$ fraction predominated, whereas in soil washed in dynamic conditions the $\mathrm{F} 1$ fraction of $\mathrm{Pb}$ predominated. The results indicate that batch soil washing was more favourable for $\mathrm{Pb}$ removal from individual fractions with all tested WAs. 
a)

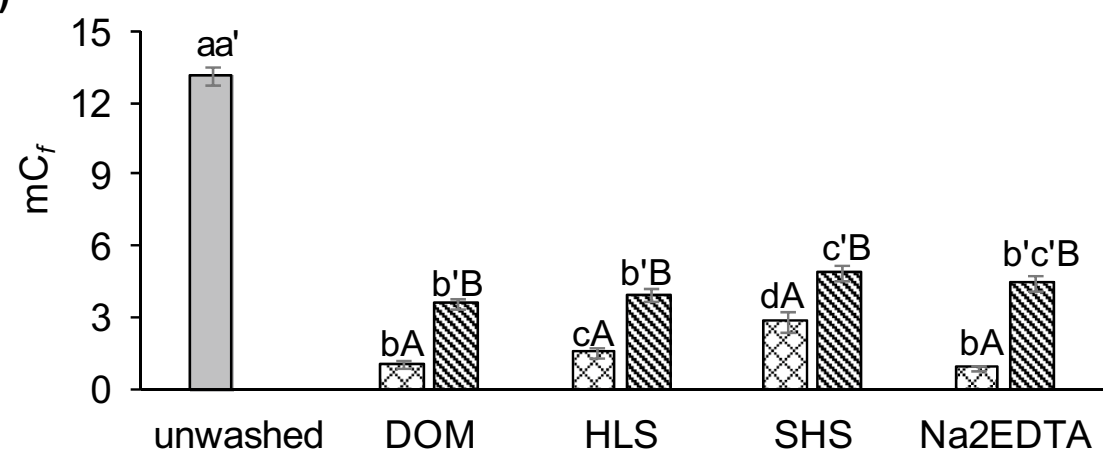

b)

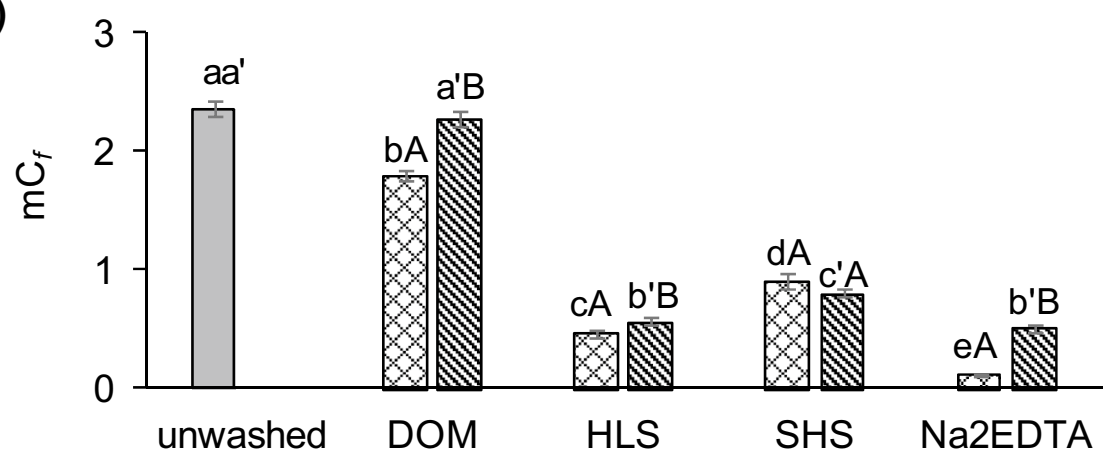

c)

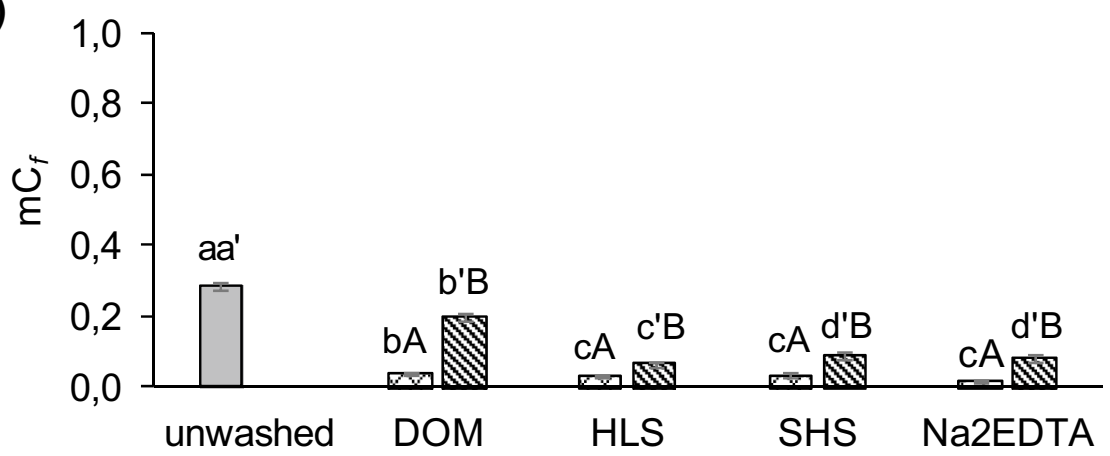

d)

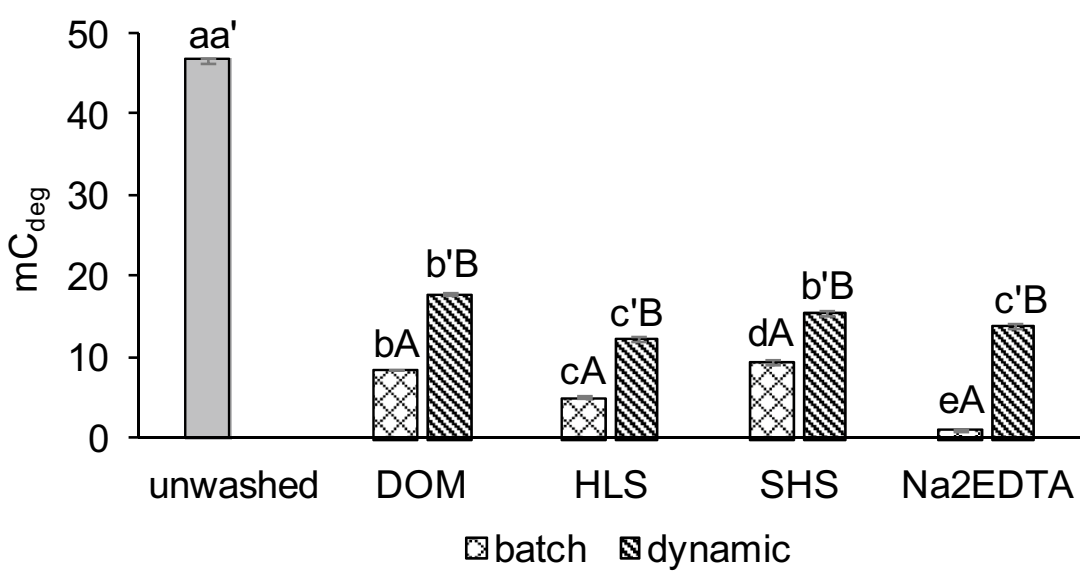

Figure 3. Assessment of the soil pollution with metals based on modified contamination factor $\left(\mathrm{mC}_{f}\right)$ and modified contamination degree $\left(\mathrm{mC}_{\text {deg }}\right)$ : (a) $\mathrm{mC}_{f}$ for $\mathrm{Cu},(\mathbf{b}) \mathrm{mC}_{f}$ for $\mathrm{Pb},(\mathbf{c}) \mathrm{mC}_{f}$ for $\mathrm{Zn},(\mathbf{d}) \mathrm{mC}_{\text {deg. }}$. Significant differences (mean $\pm \mathrm{SD}, \mathrm{p}<0.05$, Statistica 13.1) for $\mathrm{mC}_{f}$ and $\mathrm{mC}_{\text {deg }}$ between soils washed under batch conditions $(\mathrm{abc})$, between soils washed under dynamic conditions ( $\mathrm{a}^{\mathrm{b}} \mathrm{b} \mathrm{c}^{\prime}$ ) and between washing conditions with the use of the same washing solution $(\mathrm{AB})$ are marked with specific letters. 

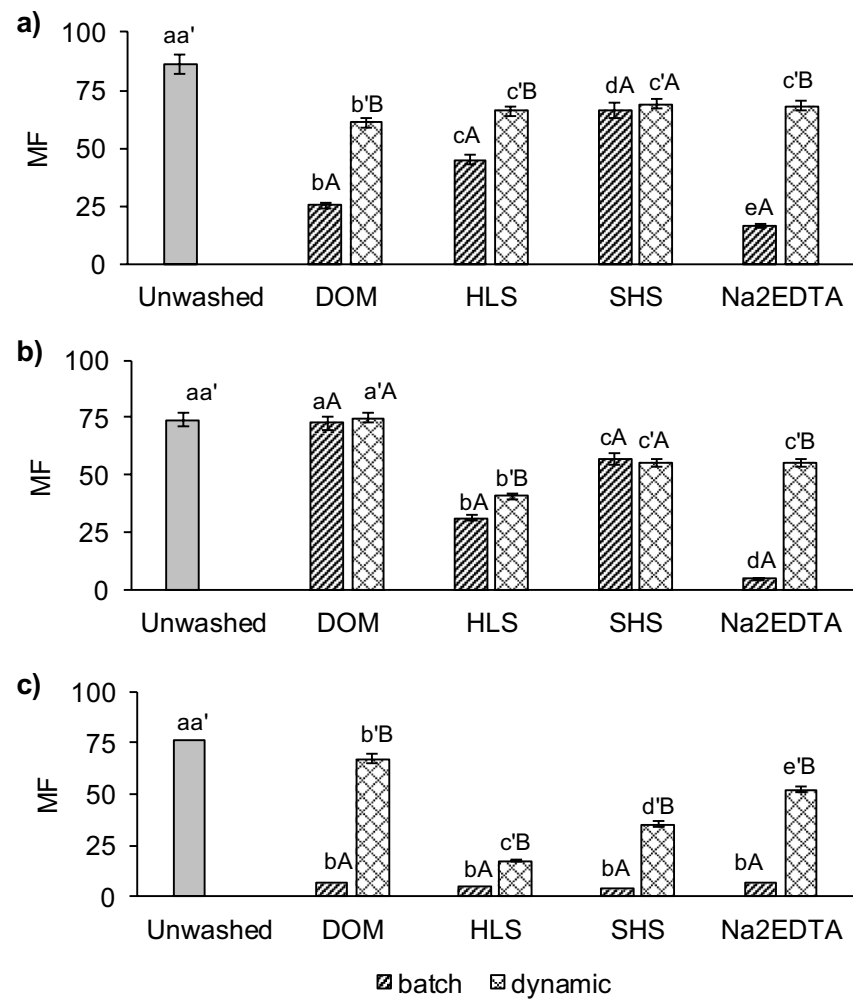

Figure 4. Mobility factor $(M F)$ in unwashed soil and soil treated with different washing agents: (a) $\mathrm{Cu},(\mathbf{b}) \mathrm{Pb}$, and (c) Zn. Significant differences (mean \pm SD, p $<0.05$, Statistica 13.1) for $M F$ between soils washed under batch conditions $(\mathrm{abc})$, between soils washed under dynamic conditions ( $\left.\mathrm{a}^{\prime} \mathrm{b}^{\prime} \mathrm{c}^{\prime}\right)$ and between washing conditions with the use of the same washing solution $(\mathrm{AB})$ are marked with specific letters.

The highest changes in fractional distribution were observed for $\mathrm{Zn}$. Its distribution patterns in batchwashed soil with DOM, HLS, SHS and $\mathrm{Na}_{2}$ EDTA were similar, with the largest share of $\mathrm{Zn}$ in F4 fraction (22.4-47.5 $\mathrm{mg} \mathrm{kg}^{-1}$ ). In contrast, distribution patterns of $\mathrm{Zn}$ in dynamic-washed soil were more differential. Fraction F4, representing the lowest potential environmental risk, constituted the largest share in HLS-washed soil and in SHS-washed soil. However, the most mobile F1 fraction of Zn prevailed in DOM- and $\mathrm{Na}_{2}$ EDTA-washed soil, followed by SHS- and HLS-washed soil (Table 2).

Suitability of different environmental indices for assessment the quality of washed soil. Soil pollution with metals. The soil pollution with metals before and after remediation was assessed with $\mathrm{mC}_{f}$ and $\mathrm{mC}_{\text {deg }}$ indices. With the $\mathrm{mC}_{f}$, unwashed soil characterized with different pollution levels for individual metals, from extreme contamination for $\mathrm{Cu}\left(\mathrm{mC}_{f}=13.1\right)$ (Fig. 3a) to moderate/strongly contaminated for $\mathrm{Pb}\left(\mathrm{mC}_{f}=2.4\right)$ (Fig. 3b). The soil has shown lack of contamination with $\mathrm{Zn}\left(\mathrm{mC}_{f}=0.28\right)$ (Fig. 3c).

Soil washing had a great effect on decreasing of $m C_{f}$ : higher decrease was observed in soil after batch than dynamic washing. In soil after batch washing with DOM and HLS, Cu showed weak to moderate contamination, however after washing with SHS soil was still highly contaminated with $\mathrm{Cu}\left(\mathrm{m} C_{f}=2.8\right)$. In soil washed under dynamic conditions with all WAs, the $\mathrm{mC}_{f}$ for $\mathrm{Cu}$ was above 3 , reflecting strong to extreme contamination (Fig. 3a). For Pb, only soil washed with DOM under batch and dynamic conditions did not meet soil quality standards for industrial area $\left(\mathrm{mC}_{f}=1.8\right.$ for batch washing and $\mathrm{mC}_{f}=2.3$ for dynamic washing) (Fig. $\left.3 \mathrm{c}\right)$. After washing with other WAs, $\mathrm{m} C_{f}$ was $<1$, meaning that soil met the national quality standard for industrial sites.

Assessing the soil contamination in relation to all metals ( $\mathrm{as} \mathrm{mC}_{\text {deg }}$ ), only soil washed with $\mathrm{Na}_{2} \mathrm{EDTA}$ under batch washing met the quality standards for industrial areas. In other soil samples, $\mathrm{m} C_{\text {deg }}$ was greater than 3 (from 5.0 to 18) (Fig. 3d). The results confirmed that total metal concentration is important for the efficiency of soil remediation and decreasing soil pollution level. Metal occurring at the highest concentration in soil before remediation (in this case $\mathrm{Cu}$ ), affects mostly the $\mathrm{mC}_{\text {deg }}$ in remediated soil.

The necessity of modification of original pollution indices $\left(C_{f}\right.$ and $\left.C_{d e g}\right)$ given by Hakanson ${ }^{21}$ resulted from the fact that these indices were dedicated to sediments. Moreover, the classification of $C_{f}$ and $C_{d e g}$ reflects the lower values of metal concentrations in contaminated sediments. Thus, the use of this classification for highly contaminated soils can be confused. For example, in this study $\mathrm{Cu}$ concentration in contaminated soil was $7874.5 \mathrm{mg} \mathrm{kg}^{-1}$ (13.1 times higher than $\mathrm{OME}^{37}$ limit), while $\mathrm{Zn}$ concentration was $566.1 \mathrm{mg} \mathrm{kg}^{-1}$ (3.5 times lower than $\mathrm{OME}^{37}$ limit). Calculated values of the original $C_{f}$ for $\mathrm{Cu}$ and $\mathrm{Zn}$ were 787.4 and 6.4, respectively and in both cases, they indicated very high contamination $\left(C_{f} \geq 6\right)$. Another example is for soil washed in batch 

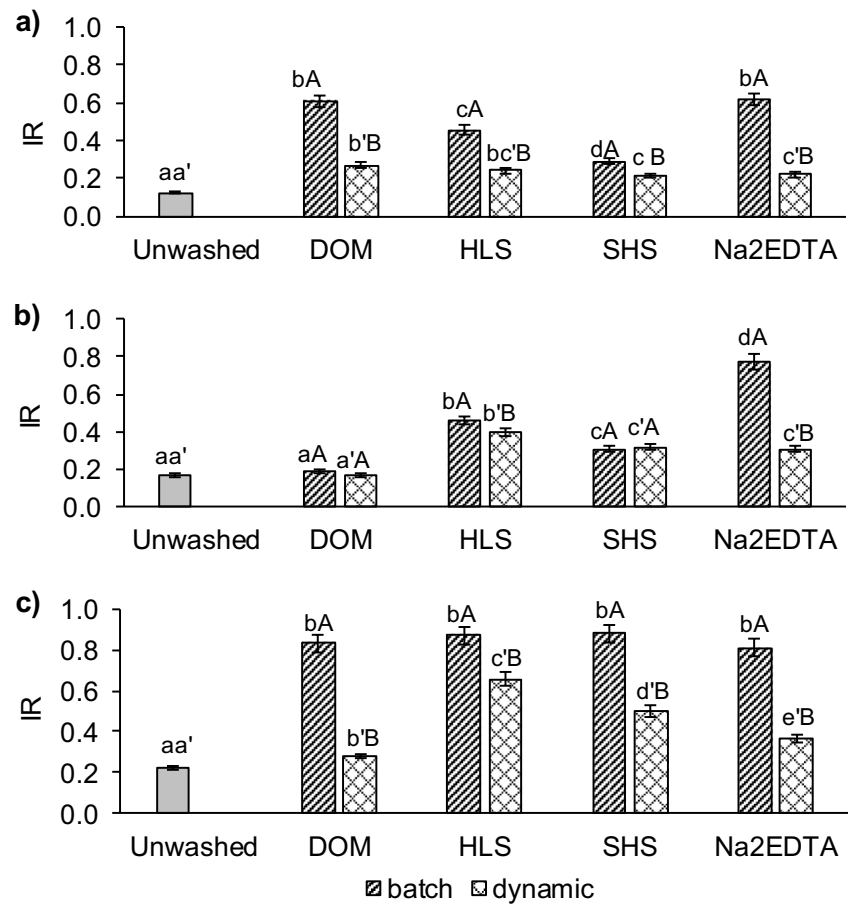

Figure 5. Assessment of the strength of metals bonding (as $I R$ ) in unwashed soil and soil treated with different washing agents: (a) $\mathrm{Cu},(\mathbf{b}) \mathrm{Pb}$, and (c) $\mathrm{Zn}$. Significant differences (mean $\pm \mathrm{SD}, \mathrm{p}<0.05$, Statistica 13.1) for $I R$ between soils washed under batch conditions $(\mathrm{abc})$, between soils washed under dynamic conditions (a'b'c') and between washing conditions with the use of the same washing solution $(\mathrm{AB})$ are marked with specific letters.

and dynamic conditions with $\mathrm{Na}_{2}$ EDTA, for which the residual $\mathrm{Cu}$ concentration was $529.1 \mathrm{mg} \mathrm{kg}^{-1}\left(C_{f}=52.9\right)$ and $2659.5 \mathrm{mg} \mathrm{kg}^{-1}\left(C_{f}=265.9\right)$, respectively, indicating very high contamination $\left(C_{f} \geq 6\right)$ in soil washed in both conditions.

The strength of metal binding in soil. Mobility factor $(M F)$. In the present study, all metals in contaminated soil were highly mobile $(74 \%<M F<86 \%)$ (Fig. 4). Such superior values of the $M F$ for $\mathrm{Cu}, \mathrm{Pb}$ and $\mathrm{Zn}$ were associated with high share of metals in the exchangeable and acid soluble (F1) fraction. Metals in this fraction are bound to soil constituents with weak bonds and thus they are highly mobile ${ }^{51}$.

The values of $M F$ have dropped significantly after washing, especially in batch-washed soil. The WAs had different ability to decrease the $M F$ for individual metals. For $\mathrm{Cu}$, the lowest $M F$ s were in DOM-and $\mathrm{Na}_{2}$ EDTA-washed soil (Fig. $4 \mathrm{a}$ ). The low Cu mobility that has been observed for these agents corresponded to high metal stability in soil (as IR). In the case of HLS and SHS, the MFs were still high (45\% and 66\%, respectively). After soil washing under dynamic conditions, the $M F$ s for $\mathrm{Cu}$ were higher for DOM, HLS and $\mathrm{Na}_{2}$ EDTA than after washing under batch conditions, and they did not differ statistically ( $M F 67.7 \%$, on average) (Fig. 4a). Comparable MFs for $\mathrm{Cu}$ were obtained in soil after washing with SHS under batch and dynamic conditions.

The highest effect on the $M F$ decrease for Pb had HLS, SHS and $\mathrm{Na}_{2}$ EDTA. It worth noticing that in soil washed with $\mathrm{Na}_{2}$ EDTA under batch conditions, the $M F$ for $\mathrm{Pb}$ was very low (5.2\%), however, in soil washed under dynamic conditions it was 10 times higher $(M F=55.4 \%)$. In the case of HLS, the difference in MFs for both washing conditions was 9.5\%, and $\mathrm{Pb}$. For DOM and SHS, the conditions of soil washing did not affect the $M F$ values of $\mathrm{Pb}$. In soil washed with $\mathrm{DOM}$, the $M F$ of $\mathrm{Pb}$ was comparable as in unwashed soil (Fig. $4 \mathrm{~b}$ ).

The effect of washing conditions on the changes in $M F$ was the greatest for $\mathrm{Zn}$. With all WAs, the $M F$ decreased from very high to low $(5.4 \%$, on average; $\mathrm{p}>0.05)$ under batch soil washing. Despite decreasing the $M F$ of $\mathrm{Zn}$ under dynamic conditions, the $\mathrm{Zn}$ mobility was still high for DOM-washed soil $(M F=67.1 \%)$ and $\mathrm{Na}_{2}$ EDTA-washed soil $(M F=52.2 \%)$. The use of HLS and SHS led to decrease $\mathrm{Zn}$ mobility to low and medium level, respectively (Fig. 4c).

High values of the $M F$ are typical for highly metal-contaminated soils. Kulikowska et al. ${ }^{18}$ demonstrated that in soil from metallurgical area in Poland, $\mathrm{Cu}$ and $\mathrm{Zn}$ showed very high mobility $(M F)$, i.e. 73.1 and $70.6 \%$, respectively. Cheng et al. ${ }^{52}$ found high $M F s$ for $\mathrm{Cu}, \mathrm{Ni}$ and $\mathrm{Zn}$, i.e. $68 \%, 64 \%$ and $53 \%$, respectively in soil from the electroplating factory (Dongguan City, China). The values of the $M F$ for $\mathrm{Cu}, \mathrm{Ni}$ and $\mathrm{Zn}$ were significantly decreased after soil batch washing with mixture of EDTA and oxalic acid to $22 \%, 25 \%$ and $23 \%$ for $\mathrm{Cu}$, Ni and $\mathrm{Zn}$, respectively. Decrease in metal mobility in soil after remediation is typical phenomenon. Gusiatin and Klimiuk ${ }^{25}$ demonstrated that significant decreasing of the $M F$ values can be obtained through multiple batch soil washing. In soil spiked with $\mathrm{Cu}, \mathrm{Cd}$ and $\mathrm{Zn}$, the metals presented very high mobility $(61 \%<M F<84 \%)$, which was decreased below $10 \%$ for $\mathrm{Cu}$ and $\mathrm{Cd}$ and below $20 \%$ for $\mathrm{Zn}$ after triple soil washing with saponin 


\begin{tabular}{|c|c|c|c|c|c|c|c|c|c|}
\hline Metal & $\begin{array}{l}\text { Washing } \\
\text { mode }\end{array}$ & WA & $\mathbf{T}_{\mathbf{r}}$ & $C_{f}$ & $\mathbf{E}_{\mathbf{r}, \mathbf{Z}}$ & $\mathbf{m} C_{f}$ & $\mathbf{E}_{\mathrm{r}, \mathrm{m}}$ & $\mathbf{R} \mathbf{I}_{\mathbf{Z}}$ & $\mathbf{R} \mathbf{I}_{\mathrm{m}}$ \\
\hline \multirow{9}{*}{$\mathrm{Cu}$} & \multirow{5}{*}{ batch } & unwashed & \multirow{9}{*}{5} & 787.5 & 3937.3 & 13.1 & 65.6 & & \\
\hline & & DOM & & 60.1 & 300.3 & 1.0 & 5.0 & & \\
\hline & & HLS & & 90.7 & 453.5 & 1.5 & 7.6 & & \\
\hline & & SHS & & 168.5 & 842.6 & 2.8 & 14.0 & & \\
\hline & & $\mathrm{Na}_{2}$ EDTA & & 52.9 & 264.6 & 0.9 & 4.4 & & \\
\hline & \multirow{4}{*}{ dynamic } & DOM & & 215.4 & 1076.8 & 3.6 & 17.9 & & \\
\hline & & HLS & & 234.4 & 1171.8 & 3.9 & 19.5 & & \\
\hline & & SHS & & 291.8 & 1459.0 & 4.9 & 24.3 & & \\
\hline & & $\mathrm{Na}_{2}$ EDTA & & 266.0 & 1329.8 & 4.4 & 22.2 & & \\
\hline \multirow{9}{*}{$\mathrm{Pb}$} & \multirow{5}{*}{ batch } & unwashed & \multirow{9}{*}{5} & 40.4 & 202.0 & 2.4 & 11.8 & & \\
\hline & & DOM & & 30.8 & 153.8 & 1.8 & 9.0 & & \\
\hline & & HLS & & 8.0 & 40.2 & 0.5 & 2.3 & & \\
\hline & & SHS & & 15.6 & 78.0 & 0.9 & 4.5 & & \\
\hline & & $\mathrm{Na}_{2}$ EDTA & & 2.0 & 10.2 & 0.1 & 0.6 & & \\
\hline & \multirow{4}{*}{ dynamic } & DOM & & 39.0 & 195.0 & 2.3 & 11.4 & & \\
\hline & & HLS & & 9.6 & 48.2 & 0.6 & 2.8 & & \\
\hline & & SHS & & 13.7 & 68.7 & 0.8 & 4.0 & & \\
\hline & & $\mathrm{Na}_{2}$ EDTA & & 8.6 & 43.0 & 0.5 & 2.5 & & \\
\hline \multirow{9}{*}{$\mathrm{Zn}$} & \multirow{5}{*}{ batch } & unwashed & \multirow{9}{*}{1} & 6.4 & 6.4 & 0.28 & 0.28 & & \\
\hline & & DOM & & 0.8 & 0.8 & 0.04 & 0.04 & & \\
\hline & & HLS & & 0.7 & 0.7 & 0.03 & 0.03 & & \\
\hline & & SHS & & 0.7 & 0.7 & 0.03 & 0.03 & & \\
\hline & & $\mathrm{Na}_{2}$ EDTA & & 0.4 & 0.4 & 0.02 & 0.02 & & \\
\hline & \multirow{4}{*}{ dynamic } & DOM & & 4.5 & 4.5 & 0.20 & 0.20 & & \\
\hline & & HLS & & 1.4 & 1.4 & 0.06 & 0.06 & & \\
\hline & & SHS & & 2.0 & 2.0 & 0.09 & 0.09 & & \\
\hline & & $\mathrm{Na}_{2}$ EDTA & & 1.8 & 1.8 & 0.08 & 0.08 & & \\
\hline \multirow{5}{*}{\multicolumn{2}{|c|}{ batch }} & \multicolumn{6}{|c|}{ unwashed } & 4145.7 & 77.7 \\
\hline & & \multicolumn{6}{|c|}{ DOM } & 454.9 & 14.0 \\
\hline & & \multicolumn{6}{|c|}{ HLS } & 494.3 & 9.9 \\
\hline & & \multicolumn{6}{|c|}{ SHS } & 921.3 & 18.6 \\
\hline & & \multicolumn{6}{|c|}{$\mathrm{Na}_{2}$ EDTA } & 275.2 & 5.0 \\
\hline \multirow{4}{*}{\multicolumn{2}{|c|}{ dynamic }} & \multicolumn{6}{|c|}{ DOM } & 1276.3 & 29.5 \\
\hline & & \multicolumn{6}{|c|}{ HLS } & 1221.4 & 22.4 \\
\hline & & \multicolumn{6}{|c|}{ SHS } & 1529.7 & 28.4 \\
\hline & & \multicolumn{6}{|c|}{$\mathrm{Na}_{2}$ EDTA } & 1374.6 & 24.8 \\
\hline \multicolumn{10}{|c|}{ Classification of $\mathrm{E}_{\mathrm{r}, \mathrm{Z}}$ and $\mathrm{E}_{\mathrm{r}, \mathrm{m}}$ : } \\
\hline & $\begin{array}{l}\text { very high } \\
\text { risk }\end{array}$ & & & & $\begin{array}{l}\text { nsiderable } \\
\text { risk }\end{array}$ & & $\begin{array}{c}\text { moderate } \\
\text { risk }\end{array}$ & & $\begin{array}{l}\text { low } \\
\text { risk }\end{array}$ \\
\hline & tion of RI & and $\mathrm{RI}_{\mathrm{m}}$ : & & & & & & & \\
\hline & $\begin{array}{r}\text { very } h \\
\text { risk }\end{array}$ & & & $\begin{array}{l}\text { siderable } \\
\text { risk }\end{array}$ & & $\begin{array}{r}\text { mode } \\
\text { ris }\end{array}$ & & & $\begin{array}{l}\text { low } \\
\text { risk }\end{array}$ \\
\hline
\end{tabular}

Table 3. Comparison of potential ecological risk factors $\left(E_{r, \mathrm{Z}}, E_{r, \mathrm{~m}}\right)$ and potential ecological risk indices $\left(R I_{\mathrm{Z}}\right.$, $\left.R I_{\mathrm{m}}\right)$ in soil before and after washing.

biosurfactant. Also, Wang et al. ${ }^{53}$ showed that batch washing was very effective in decreasing $\mathrm{Pb}$ mobility with $\mathrm{N}, \mathrm{N}$-bis (carboxymethyl)-L-glutamic acid in mine soil, from 80 to $17 \%$.

Reduced partition index $(I R)$. One of the tools to evaluate the stability of metals in soil is the $I R$ index based on the metal distribution patterns $s^{24,25}$. Originally, the index was applied for assessment of metal stability in soil amended with different additives. Nowadays, it can be used also for soil remediated with soil washing ${ }^{25}$. An increase of the $I R$ indicates metals redistribution in soil, from less to more stable fractions. In the case of BCR sequential scheme of metal fractionation, the F1 fraction is mobile, the F2 and F3 fractions are potentially mobile, and the F4 fraction is stable. Thus, the considerable increase of the $I R$ is favoured by the increase of metal share in the most stable fraction.

With the use of the $I R$ index the changes in metal stability were captured. The values of the $I R$ index for unwashed soil and soil washed with different WAs are shown in Fig. 5. The results indicate that $I R$ values in unwashed soil were relatively low $(I R=0.12-0.22)$ indicating low stability of all metals. Soil washing increased the $I R$ for all metals, except for $\mathrm{Pb}$ in DOM-washed soil $(I R<0.3)$. In general, metals in soil from batch washing showed higher bonding intensities compared to soil from dynamic washing. In additions, metals differed in bonding intensities in washed soil. The differences were strongly related to metal distribution patterns ("Patterns of metal distribution in soil washed under batch and dynamic conditions" section). Batch washing with DOM and $\mathrm{Na}_{2}$ EDTA resulted in high stability of $\mathrm{Cu}(I R=0.61$ for both agents $)$, whereas the stability of Cu in soil from dynamic washing was 2.6 times lower ( $I R=0.26$ for $\mathrm{DOM}$ and 0.22 for $\mathrm{Na}_{2} \mathrm{EDTA}$ ). For $\mathrm{Pb}$, the greatest differences in the metal stability between batch- and dynamic-washed soil (by $I R=0.47$ ) was indicated for $\mathrm{Na}_{2} \mathrm{EDTA}_{\text {. }}$ 
Medium Pb stability was in soil washed with SS_WAs under batch and dynamic conditions ( $I R=0.5$ and 0.4 for HLS and $I R=0.33$ and 0.32 for SHS, respectively).

Batch soil washing was especially effective for $\mathrm{Zn}$ removal from mobile and potentially mobile fractions by all WAs, which resulted in high stability $(I R>0.8)$. In contrast, the Zn stability in soil after dynamic washing ranged from low for DOM $(I R=0.28)$ to elevated for HLS $(I R=0.66)$.

Studies evaluating the metal stability (based on $I R$ ) in soils after washing were conducted by Gusiatin et al. ${ }^{54}$. The authors have found that application of different biosurfactants as WAs (saponin, tannic acid, rhamnolipids) significantly increased the stability of $\mathrm{Cd}, \mathrm{Cu}, \mathrm{Ni}, \mathrm{Pb}$ and $\mathrm{Zn}$ (based on the $\mathrm{IR}$ ) in spiked soil. Similar observations were made by Cheng et al..$^{52}$, who noticed an increase in the $I R$ index in soils after washing with a mixture of EDTA and organic acids. The increase was associated with the effective removal of $\mathrm{Cu}, \mathrm{Ni}$, and $\mathrm{Zn}$, mainly from F1 fraction, and increasing the share of the most stable fractions, which were removed less efficiently.

Ecological risk assessment of metals. In this study, calculated values of $E_{r, \mathrm{Z}}$ and $E_{r \mathrm{~m}}$ for individual metals, and the values of $R I_{\mathrm{Z}}$ and $R I_{\mathrm{m}}$ for overall risk assessment are shown in Table 3. Based on the values of the indices calculated for contaminated soil and soil washed under different hydrodynamic conditions with conventional and next-generation WAs, differing in the efficiency of soil remediation, it turned out that neither of these two indices is universal. The most visible discrepancy of these indices for remediated soil was observed for $\mathrm{Cu}$. Despite a 13-15 fold decrease in the total Cu concentration in soil after washing with DOM and $\mathrm{Na}_{2} \mathrm{EDTA}$, and the decrease in $E_{r, Z}$ from 3937.3 to 300.3 and 264.6, respectively, the potential ecological risk was still very high (according to $Z$ hu et al. ${ }^{41}, E_{r, Z} \geq 120$ means very high potential ecological risk). Similar discrepancy was demonstrated for $\mathrm{Cu}$ removed under dynamic soil washing. For $E_{r, \mathrm{~m}}$, its discrepancy was noted for $\mathrm{Pb}$ in contaminated soil and in soil after washing. In both soils, $\mathrm{Pb}$ has shown the same potential ecological risk. This means that both $E_{r, \mathrm{Z}}$ and $E_{r, \mathrm{~m}}$ cannot be considered as universal for ecological risk assessment in soil contaminated with metals and soil remediated in batch and dynamic soil washing with SS_WAs and $\mathrm{Na}_{2}$ EDTA under specific operational conditions.

\section{Conclusions}

Considering legislative purposes of soil remediation, in this study, the use of current metal concentration in relation to permissible levels in soil instead of geochemical background/pre-industrial level was proposed for calculation the indices of soil pollution after remediation. In addition, own classification scale for soil pollution indices and metal stability in soil was proposed. The $m C_{f}$ and $m C_{\text {deg }}$ were useful to identify soil pollution with metals. The $\mathrm{mC}_{f}$ together with the $I R$ characterize individual metals in terms of their pollution and stability degree in soil. The indices clearly distinguished the environmental quality of soil after remediation under different hydrodynamic washing conditions with $\mathrm{Na}_{2}$ EDTA and SS_WAs. Thus, they may be an useful tool for assessment of soil remediation with different WAs. Their usefulness requires further verification in case of treatment of other types of soils contaminated with different levels of metals and/or metalloids.

Received: 28 July 2020; Accepted: 10 November 2020

Published online: 25 November 2020

\section{References}

1. Bolan, N. et al. Remediation of heavy metal(loid)s contaminated soils: To mobilize or to immobilize?. J. Hazard. Mater. 266, 141-166 (2014).

2. Lee, D.-H. Experimental Investigation of the Removal of Hydrophobic Organic Compounds from Two Iowa Soils Using Food Grade Surfactants and Recovery of Used Surfactants. (Iowa State University, 1999).

3. Gusiatin, Z. M., Kulikowska, D. \& Klik, B. New-generation washing agents in remediation of metal-polluted soils and methods for washing effluent treatment: A review. Int. J. Environ. Res. Public Health 17(17), 6220 (2020).

4. Befkadu, A. A. \& Quanyuan, C. H. E. N. Surfactant-enhanced soil washing for removal of petroleum hydrocarbons from contaminated soils: A review. Pedosphere 28(3), 383-410 (2018).

5. Dermont, G., Bergeron, M., Mercier, G. \& Richer-Laflèche, M. Soil washing for metal removal: A review of physical/chemical technologies and field applications. J. Hazard. Mater. 152, 1-31 (2008).

6. USEPA. Contaminated Land: Applications in the Real Environments: Understanding Soil Washing. (2007).

7. Jalilian Ahmadkalaei, S. P. Integrated physical-Fenton remediation of petroleum-contaminated soil using ethyl lactate as a green solvent. (University of Nottingham, 2018).

8. Banzhaf, S. \& Hebig, K. H. Use of column experiments to investigate the fate of organic micropollutants: A review. Hydrol. Earth Syst. Sci. 20, 3719-3737 (2016).

9. Wasay, S. A., Barrington, S. \& Tokunaga, S. Efficiency of GAC for treatment of leachate from soil washing process. Water Air Soil Pollut. 116, 449-460 (1999).

10. Begum, Z. A. et al. Remediation of toxic metal contaminated soil by washing with biodegradable aminopolycarboxylate chelants. Chemosphere 87, 1161-1170 (2012).

11. Liu, C. C. \& Lin, Y. C. Reclamation of copper-contaminated soil using EDTA or citric acid coupled with dissolved organic matter solution extracted from distillery sludge. Environ. Pollut. 178, 97-101 (2013).

12. Ferraro, A., Fabbricino, M., van Hullebusch, E. D. \& Esposito, G. Investigation of different ethylenediamine- $N, N^{\prime}$-disuccinic acidenhanced washing configurations for remediation of a Cu-contaminated soil: Process kinetics and efficiency comparison between single-stage and multi-stage configurations. Environ. Sci. Pollut. Res. 24, 21960-21972 (2017).

13. Andreozzi, R. et al. Simultaneous removal of $\mathrm{Cr}$ (III) from high contaminated soil and recovery of lactic acid from the spent solution. J. Environ. Manag. 268, 110584 (2020).

14. Kulikowska, D., Gusiatin, Z. M., Bułkowska, K. \& Klik, B. Feasibility of using humic substances from compost to remove heavy metals $(\mathrm{Cd}, \mathrm{Cu}, \mathrm{Ni}, \mathrm{Pb}, \mathrm{Zn})$ from contaminated soil aged for different periods of time. J. Hazard. Mater. 300, 882-891 (2015).

15. Wang, Y. et al. Characterization of spectral responses of dissolved organic matter (DOM) for atrazine binding during the sorption process onto black soil. Chemosphere 180, 531-539 (2017).

16. Chiang, P.-N. et al. Reclamation of zinc-contaminated soil using a dissolved organic carbon solution prepared using liquid fertilizer from food-waste composting. J. Hazard. Mater. 301, 100-105 (2016). 
17. Meng, F. et al. Humic substances as a washing agent for Cd-contaminated soils. Chemosphere 181, 461-467 (2017).

18. Kulikowska, D., Klik, B. K., Gusiatin, Z. M. \& Jabłoński, R. Sewage sludge can provide a washing agent for remediation of soil from a metallurgical area. CATENA 173, 22-28 (2019).

19. Kowalska, J. B., Mazurek, R., Gąsiorek, M. \& Zaleski, T. Pollution indices as useful tools for the comprehensive evaluation of the degree of soil contamination: A review. Environ. Geochem. Health 40, 2395-2420 (2018).

20. Muller, G. Index of geoaccumulation in sediments of the Rhine river. GeoJournal 2, 108-118 (1969).

21. Hakanson, L. An ecological risk index for aquatic pollution control. A sedimentological approach. Water Res. 14, 975-1001 (1980).

22. Sutherland, R. A. Bed sediment-associated trace metals in an urban stream, Oahu Hawaii. Environmental Geol. 39, 611-627 (2000).

23. Eliana Andrea, M. M., Ana Carolina, T. E., Tito José, C. B., José Luis, M. N. \& Luis Carlos, G. M. Evaluation of contaminants in agricultural soils in an Irrigation District in Colombia. Heliyon 5, e02217 (2019).

24. Han, F. X. et al. New approach to studies of heavy metal redistribution in soil. Adv. Environ. Res. 8, 113-120 (2003).

25. Gusiatin, Z. M. \& Klimiuk, E. Metal (Cu, Cd and $\mathrm{Zn}$ ) removal and stabilization during multiple soil washing by saponin. Chemosphere 86, 383-391 (2012).

26. Hołtra, A. \& Zamorska-Wojdyła, D. The pollution indices of trace elements in soils and plants close to the copper and zinc smelting works in Poland's Lower Silesia. Environ. Sci. Pollut. Res. 27, 16086-16099 (2020).

27. Wei, M., Chen, J. \& Wang, X. Removal of arsenic and cadmium with sequential soil washing techniques using Na2EDTA, oxalic and phosphoric acid: Optimization conditions, removal effectiveness and ecological risks. Chemosphere 156, 252-261 (2016).

28. Wei, M. \& Chen, J. Influence of multi-step washing using Na2EDTA, oxalic acid and phosphoric acid on metal fractionation and spectroscopy characteristics from contaminated soil. Environ. Sci. Pollut. Res. 23, 23123-23133 (2016).

29. Chaiyaraksa, C. \& Sriwiriyanuphap, N. Batch washing of cadmium from soil and sludge by a mixture of Na2S2O5 and Na2EDTA. Chemosphere 56, 1129-1135 (2004).

30. Klik, B., Kulikowska, D., Gusiatin, Z. M. \& Pasieczna-Patkowska, S. Washing agents from sewage sludge: Efficiency of Cd removal from highly contaminated soils and effect on soil organic balance. J. Soils Sediments 20, 284-296 (2020).

31. Naghipour, D., Gharibi, H., Taghavi, K. \& Jaafari, J. Influence of EDTA and NTA on heavy metal extraction from sandy-loam contaminated soils. J. Environ. Chem. Eng. 4, 3512-3518 (2016).

32. Diatta, J., Chudzinska, E. \& Wirth, S. Assessment of heavy metal contamination of soils impacted by a zinc smelter activity. J. Elementol. 13, 5-16 (2008).

33. Demie, G. Analyzing soil contamination status in garage and auto mechanical workshops of Shashemane City: Implication for hazardous waste management. Environ. Syst. Res. 4, 1-9 (2015).

34. Nouri, M. \& Haddioui, A. Assessment of metals contamination and ecological risk in ait ammar abandoned iron mine soil, Moroco. Ekol. Bratisl. 35, 32-49 (2016).

35. Salman, S. A., Zeid, S. A. M., Seleem, E.-M.M. \& Abdel-Hafiz, M. A. Soil characterization and heavy metal pollution assessment in Orabi farms, El Obour, Egypt. Bull. Natl. Res.Centre 43, 1-13 (2019).

36. EPL. Polish Environmental Protection Law. J Law. Dz.U. 2014, (2014).

37. OME. Ordinance of the Minister of Environment on soil and ground quality standards. J Law. 395, 1-86 (2016).

38. Guo, W., Liu, X., Liu, Z. \& Li, G. Pollution and potential ecological risk evaluation of heavy metals in the sediments around Dongjiang Harbor, Tianjin. In Procedia Environmental Sciences 2, 729-736 (Elsevier, 2010).

39. Feng, C. et al. Feasibility of four wastes to remove heavy metals from contaminated soils. J. Environ. Manag. 212, 258-265 (2018).

40. Zhu, H.-N. et al. Ecological risk assessment of heavy metals in sediments of Xiawan Port based on modified potential ecological risk index. Trans. Nonferrous Metals Soc. China 22, 1470-1477 (2012).

41. Zhu, W., Bian, B. \& Li, L. Heavy metal contamination of road-deposited sediments in a medium size city of China. Environ. Monit. Assess. 147, 171-181 (2008).

42. Ostrowska, A., Gawlinski, S. \& Szczubiałka, Z. Analysis of soils and plants. Institute of Environmental Protection-National Research Institute (Institute of Environmental Protection-National Research Institute, 1991).

43. Pueyo, M. et al. Use of the modified BCR three-step sequential extraction procedure for the study of trace element dynamics in contaminated soils. Environ. Pollut. 152, 330-341 (2008).

44. Voegelin, A., Barmettler, K. \& Kretzschmar, R. Heavy Metal Release from Contaminated Soils. J. Environ. Qual. 32, 865-875 (2003).

45. Hauser, L., Tandy, S., Schulin, R. \& Nowack, B. Column extraction of heavy metals from soils using the biodegradable chelating agent EDDS. Environ. Sci. Technol. 39, 6819-6824 (2005).

46. Mgbeahuruike, L. U., Barrett, J., Potgieter, H. J., van Dyk, L. \& Potgieter-Vermaak, S. S. A comparison of batch, column and heap leaching efficiencies for the recovery of heavy metals from artificially contaminated simulated soil. J. Environ. Prot. 10, 632-650 (2019).

47. Liu, C. C. \& Chen, G. B. Reclamation of cadmium-contaminated soil using dissolved organic matter solution originating from wine-processing waste sludge. J. Hazard. Mater. 244, 645-653 (2013).

48. Minkina, T. M., Motusova, G. V., Nazarenko, O. G. \& Mandzhieva, S. S. Heavy Metal Compounds in Soil: Transformation Upon Soil Pollution and Ecological Significance (Nova Science Publishers, New York, 2010).

49. Wali, A., Colinet, G. \& Ksibi, M. Speciation of heavy metals by modified BCR sequential extraction in soils contaminated by phosphogypsum in Sfax, Tunisia. Environ. Res. Eng. Manag. 70, 14-26 (2015).

50. Saeedi, M. \& Jamshidi-Zanjani, A. Development of a new aggregative index to assess potential effect of metals pollution in aquatic sediments. Ecol. Ind. 58, 235-243 (2015).

51. Sungur, A., Soylak, M. \& Özcan, H. Chemical fractionation, mobility and environmental impacts of heavy metals in greenhouse soils from Çanakkale, Turkey. Environ. Earth Sci. 75, 1-11 (2016).

52. Cheng, S. et al. The removal of $\mathrm{Cu}, \mathrm{Ni}$, and $\mathrm{Zn}$ in industrial soil by washing with EDTA-organic acids. Arab. J. Chem. 13, 5160-5170 (2020).

53. Wang, G. et al. Heavy metal removal by GLDA washing: Optimization, redistribution, recycling, and changes in soil fertility. Sci. Total Environ. 569, 557-568 (2016).

54. Gusiatin, Z. M., Radziemska, M. \& Żochowska, A. Sequential soil washing with mixed biosurfactants is suitable for simultaneous removal of multi-metals from soils with different properties, pollution levels and ages. Environ. Earth Sci. 78, 528 (2019).

\section{Acknowledgements}

This study is a result of the research project No. 2017/27/N/ST8/00255 funded by the National Science Centre. This study financially co-supported by Minister of Science and Higher Education in the range of the program entitled "Regional Initiative of Excellence" for the years 2019-2022, Project No. 010/RID/2018/19, amount of funding 12,000,000 PLN.

\section{Author contributions}

B.K.K. conducted the analysis and writing the paper. D.K. and Z.M.G. conceptualized and designed the study, writing the paper. 


\section{Competing interests}

The authors declare no competing interests.

\section{Additional information}

Correspondence and requests for materials should be addressed to B.K.K.

Reprints and permissions information is available at www.nature.com/reprints.

Publisher's note Springer Nature remains neutral with regard to jurisdictional claims in published maps and institutional affiliations.

(c) (1) Open Access This article is licensed under a Creative Commons Attribution 4.0 International License, which permits use, sharing, adaptation, distribution and reproduction in any medium or format, as long as you give appropriate credit to the original author(s) and the source, provide a link to the Creative Commons licence, and indicate if changes were made. The images or other third party material in this article are included in the article's Creative Commons licence, unless indicated otherwise in a credit line to the material. If material is not included in the article's Creative Commons licence and your intended use is not permitted by statutory regulation or exceeds the permitted use, you will need to obtain permission directly from the copyright holder. To view a copy of this licence, visit http://creativecommons.org/licenses/by/4.0/.

(c) The Author(s) 2020 